\title{
openheart Association of protein-energy wasting and inflammation status with mortality after coronary revascularisation in patients on haemodialysis
}

\author{
Yoshitaka Kumada, ${ }^{1}$ Hideki Ishii (1) , ,,3 Satoru Oshima, ${ }^{4}$ Ryuta Ito, ${ }^{4}$ \\ Norio Umemoto, ${ }^{4}$ Hiroshi Takahashi (D) , ${ }^{5}$ Toyoaki Murohara ${ }^{2}$
}

To cite: Kumada Y, Ishii H, Oshima S, et al. Association of protein-energy wasting and inflammation status with mortality after coronary revascularisation in patients on haemodialysis. Open Heart 2020;7:e001276. doi:10.1136/ openhrt-2020-001276

A part of this study was previously presented at European Society of Cardiology Congress 2017.

Received 25 February 2020 Revised 21 May 2020 Accepted 27 May 2020
(A) Check for updates

(c) Author(s) (or their employer(s)) 2020. Re-use permitted under CC BY-NC. No commercial re-use. See rights and permissions. Published by BMJ.

${ }^{1}$ Cardiovascular Surgery, Matsunami General Hospital, Hashima-gun, Gifu, Japan ${ }^{2}$ Cardiology, Nagoya University Graduate School of Medicine, Nagoya, Japan

${ }^{3}$ Cardiology, Fujita Health University Bantane Hospital, Nagoya, Japan

${ }^{4}$ Cardiology, Nagoya Kyoritsu Hospital, Nagoya, Aichi, Japan ${ }^{5}$ Nephrology, Fujita Health University, Toyoake, Japan

Correspondence to Dr Hiroshi Takahashi; hirotaka@ fujita-hu.ac.jp

\section{ABSTRACT}

Objective Protein-energy wasting is associated with chronic inflammation and advanced atherosclerosis in haemodialysis (HD) patients. We investigated association of geriatric nutritional risk index (GNRI), $\mathrm{C}$ reactive protein (CRP) with prediction of mortality after coronary revascularisation in chronic $\mathrm{HD}$ patients.

Methods We enrolled $721 \mathrm{HD}$ patients electively undergoing coronary revascularisation. They were divided into tertiles according to preprocedural GNRI levels (tertile 1 (T1):<91.5, T2: 91.5-98.1 and T3:>98.1) and CRP levels (T1: $\leq 1.4 \mathrm{mg} / \mathrm{L}, \mathrm{T} 2: 1.5-7.0 \mathrm{mg} / \mathrm{L}$ and $\mathrm{T} 3: \geq 7.1 \mathrm{mg} / \mathrm{L}$ ). Results Kaplan-Meier 10 years survival rates were $32.3 \%, 44.8 \%$ and $72.5 \%$ in $\mathrm{T} 1, \mathrm{~T} 2$ and $\mathrm{T} 3$ of GNRI and $60.9 \%, 49.2 \%$ and $23.5 \%$ in $\mathrm{T} 1, \mathrm{~T} 2$ and $\mathrm{T} 3$ of CRP, respectively ( $p<0.0001$ in both). Declined GNRI (HR 2.40, $95 \% \mathrm{Cl} 1.58$ to $3.74, \mathrm{p}<0.0001$ for T1 vs T3) and elevated CRP (HR 2.31, 95\% Cl 1.58 to $3.43, \mathrm{p}<0.0001$ for T3 vs T1) were identified as independent predictors of mortality. In combined setting of both variables, risk of mortality was 5.55 times higher $(95 \% \mathrm{Cl} 2.64$ to $13.6, \mathrm{p}<0.0001)$ in $\mathrm{T} 1$ of GNRI with T3 of CRP than in T3 of GNRI with T1 of CRP. Addition of GNRI and CRP in a model with established risk factors improved C-statistics (0.648 to $0.724, \mathrm{p}<0.0001$ ) greater than that of each alone.

Conclusion Preprocedural declined GNRI and elevated CRP were closely associated with mortality after coronary revascularisation in chronic HD patients. Furthermore, combination of both variables not only stratified risk of mortality but also improved the predictability.

\section{INTRODUCTION}

Over the past decade, cardiorenal interactions have been featured because patients with chronic kidney disease (CKD) frequently experience cardiovascular disease (CVD) and vice versa. ${ }^{1}$ Particularly in subjects requiring haemodialysis (HD), coronary artery disease $(\mathrm{CAD})$ reportedly presents in over half of patients, even at the beginning of HD therapy, ${ }^{2}$ and is the leading cause of death in this population. ${ }^{3}$ In such situations, coronary revascularisation with coronary artery bypass

\section{Key question}

What is already known about this subject?

- Prognosis after coronary revascularisation is consistently poorer in haemodialysis (HD) patients with coronary artery disease (CAD) compared with nonHD patients. On the other hand, the association of malnutrition and chronic inflammation status with poor prognosis has been reported in HD population.

What does this study add?

- Preprocedural declined geriatric nutritional risk index and elevated $C$ reactive protein could not only stratify the risk of cardiovascular disease-cause and all-cause mortality after coronary revascularisation but also improve the predictability in HD population with $\mathrm{CAD}$ as well as $\mathrm{HD}$ population.

How might this impact on clinical practice?

- Both variables are easily obtained from daily clinical practice, physicians should pay more attention to comorbidities in HD patients who need coronary revascularisation.

graft surgery $(\mathrm{CABG})^{4-6}$ or percutaneous coronary intervention (PCI) is performed in HD patients world wide. However, their prognosis is still markedly poorer compared with that of the general population. ${ }^{4-8}$ On the other hand, protein-energy wasting (PEW), a state of decreased body protein mass and energy fuel, is reportedly prevalent in CKD patients $^{1011}$ and consistently associated with increased risks of cardiovascular mortality. ${ }^{12}$ PEW can result not only from an inadequate diet but also be induced by inflammatory processes. ${ }^{9} 13 \quad 14$ Moreover, inflammatory status itself is associated with mortality in this population. ${ }^{15}$ In these contexts, we investigated the association of the geriatric nutritional risk index $(\mathrm{GNRI})^{16}$ as a surrogate marker of the PEW, $\mathrm{C}$ reactive protein (CRP) and their combined predictive value for CVD 
and all-cause mortality after coronary revascularisation in chronic HD patients.

\section{METHODS \\ Patients}

From April 2001 to December 2011, a total of 721 HD patients electively underwent coronary revascularisation and were enrolled in this study. In advance, patients with acute myocardial infarction, those hospitalised due to other active diseases and those with a history of malignancies were excluded. Diabetes, hypertension and dyslipidaemia were defined according to each guideline. ${ }^{17-19}$ Multivessel disease was defined as the presence of a lesion at more than two vessels among the right coronary artery, left anterior descending artery and left circumflex artery and/or left main trunk disease. The left ventricular ejection fraction (LVEF) was measured using the modified Simpson's method via ultrasonic echocardiography. In patients undergoing CABG, the off-pump technique was selected, and the internal thoracic arteries were used if possible. In patients treated with PCI, drugeluting stent (DES) was used if the patients had no contraindications.

\section{The GNRI and CRP measurements}

Blood samples to determine serum albumin and CRP levels were taken at the just preperiod of procedural day. The GNRI was calculated from the individually obtained serum albumin levels and body weight as follows, reported by Yamada $e t$ al. $^{20}$

GNRI $=[14.89 \times$ albumin $(\mathrm{g} / \mathrm{dl})]+[41.7 \times($ body weight/ideal body weight) ]

The body weight/ideal body weight was set to 1 when a patient's body weight exceeded the ideal body weight. Ideal body weight was defined as the value calculated from height and a body mass index (BMI) of $22 \mathrm{~kg} / \mathrm{m}^{2} .20$ All patients underwent HD therapy before 1 day prior procedural day, and body weight after HD therapy was used to calculate the GNRI. The serum CRP was measured using latex-enhanced highly sensitive CRP immunoassay. Thereafter, patients were divided into tertiles according to their GNRI and CRP levels.

\section{Follow-Up study}

The follow-up was concluded in December 2012. The primary endpoint was CVD-cause death, including that due to heart failure, myocardial infarction, arrhythmia, sudden death, stroke, peripheral artery disease (PAD) and other CVD-related death. The data for the endpoints were obtained from hospital charts and through telephone interviews with patients conducted by trained reviewers who were blinded to the protocol. In the present study, cases of unwitnessed death were counted as cardiac death. Second endpoint was all-cause death.

\section{Statistical analyses}

Variables with a normal distribution were expressed as mean values $\pm \mathrm{SD}$, and asymmetrically distributed data were given as the median and IQR. Differences between the groups were evaluated by the one-way analysis of variance or Kruskal-Wallis test for continuous variables and by the $\mathrm{X}^{2}$ test for categorical variables. Differences in event-free survival among the groups were examined with the Kaplan-Meier method and compared using a log-rank test. HRs (HR) and 95\% CIs were calculated for each factor via a Cox proportional hazards analysis. All baseline variables with $p<0.05$ by univariate analysis were entered into a multivariate model to determine the independent predictors for the endpoint. To assess whether the predictability for mortality would improve after the addition of the GNRI, CRP and/or both of them into a baseline model with established risk factors, we calculated the C-index, net reclassification improvement (NRI) and integrated discrimination improvement (IDI). The C-index is defined as the area under receiver-operating characteristic curves between individual predictive probabilities for mortality and the incidence of mortality and was compared among each predicting model. ${ }^{21}$ The NRI relatively indicates how many patients improve their predicted probabilities for mortality, while the IDI represents the average improvement in predicted probabilities for mortality after adding variables into the baseline model. ${ }^{22}$ Differences were considered statistically significant at $\mathrm{p}<0.05$. The statistical analyses were performed using the SAS V.6.10 software (SAS Institute).

\section{Patient and public involvement}

Patients and public were not involved in this study.

\section{RESULTS}

Of the enrolled patients, 592 patients underwent PCI and 129 patients underwent CABG based on the decision made primarily by the patients after adequate explanation by their physicians. The patients were divided into tertiles according to their GNRI levels (tertile $1(\mathrm{~T} 1):<91.5$, T2: 91.5-98.1, and T3:>98.1) and CRP levels (T1: $\leq 1.4 \mathrm{mg} / \mathrm{L}$, T2: $1.5-7.0 \mathrm{mg} / \mathrm{L}$, and $\mathrm{T} 3: \geq 7.1 \mathrm{mg} / \mathrm{al})$. The clinical characteristics of the patients are shown in table 1 . The medians of the CRP levels were $5.8(1.1-18.3) \mathrm{mg} / \mathrm{L}, 3.0$ (1.0-9.0) $\mathrm{mg} / \mathrm{L}$, and $2.1(1.0-8.0) \mathrm{mg} / \mathrm{L}$ in T1, T2 and T3 of the GNRI, respectively $(\mathrm{p}=0.0001)$. Inversely, the GNRI levels were $95.9 \pm 7.6,95.0 \pm 8.3$, and $92.6 \pm 9.8$ in T1, T2 and T3 of the CRP, respectively ( $\mathrm{p}<0.0001)$.

During the follow-up period (median: 53 months), 222 cases experienced death $(30.8 \%)$, including 125 cases of CV death (17.3\%). Also, four patients underwent renal transplantation, and were censored at the point of moving out. The Kaplan-Meier analysis showed that the 10 -year survival rate was $32.3 \%, 44.8 \%$ and $72.5 \%$ in $\mathrm{T} 1$, T2 and T3 of the GNRI and $60.9 \%, 49.2 \%$ and $23.5 \%$ in T1, T2 and T3 of the CRP, respectively $(\mathrm{p}<0.0001$ in both) (figure 1). For CVD-cause mortality, similar results were obtained $(55.8 \%, 62.7 \%$ and $80.3 \%, \mathrm{p}<0.0001$, and $76.2 \%, 66.2 \%$, and $38.7 \%, \mathrm{p}<0.0001$, respectively) (figure 2). After adjusting for age, multivessel disease, 
Table 1 Clinical characteristics

\begin{tabular}{|c|c|c|c|c|c|}
\hline & & GNRI & & & \\
\hline & $\begin{array}{l}\text { All patients } \\
(\mathrm{n}=721)\end{array}$ & $\begin{array}{l}<91.5 \\
(n=240)\end{array}$ & $\begin{array}{l}91.5-98.1 \\
(n=242)\end{array}$ & $\begin{array}{l}>98.1 \\
(n=239)\end{array}$ & $P$ value \\
\hline Male gender (\%) & 71.7 & 68.3 & 67.8 & 79.1 & 0.087 \\
\hline Age (years) & $66 \pm 10$ & $69 \pm 9$ & $66 \pm 9$ & $64 \pm 10$ & $<0.0001$ \\
\hline Duration of HD (years) & $3.8(1.2-10.4)$ & $6.1(1.2-11.6)$ & $3.9(1.6-9.4)$ & $2.8(0.5-6.5)$ & 0.036 \\
\hline Diabetes (\%) & 57.7 & 56.7 & 58.3 & 58.2 & 0.93 \\
\hline Hypertension (\%) & 59.8 & 66.3 & 59.1 & 54.0 & 0.023 \\
\hline Dyslipidaemia (\%) & 28.7 & 25.4 & 28.9 & 32.6 & 0.25 \\
\hline Smoking (\%) & 29.6 & 28.0 & 28.9 & 31.8 & 0.73 \\
\hline Body mass index $\left(\mathrm{kg} / \mathrm{m}^{2}\right)$ & $21.4 \pm 3.3$ & $18.7 \pm 2.2$ & $21.5 \pm 2.2$ & $24.2 \pm 2.8$ & $<0.0001$ \\
\hline $\operatorname{PAD}(\%)$ & 38.7 & 38.3 & 39.7 & 38.1 & 0.93 \\
\hline Stroke (\%) & 19.0 & 21.9 & 17.9 & 17.2 & 0.37 \\
\hline GNRI & $94.5 \pm 8.7$ & $85.1 \pm 5.3$ & $94.7 \pm 1.9$ & $103.8 \pm 4.8$ & $<0.0001$ \\
\hline Haemoglobin (g/dL) & $10.6 \pm 1.3$ & $10.4 \pm 1.4$ & $10.6 \pm 1.3$ & $10.7 \pm 1.2$ & 0.12 \\
\hline Albumin (g/dL) & $3.6 \pm 0.4$ & $3.3 \pm 0.3$ & $3.6 \pm 0.2$ & $3.9 \pm 0.3$ & $<0.0001$ \\
\hline Total cholesterol (mg/dL) & $168 \pm 35$ & $169 \pm 38$ & $167 \pm 34$ & $167 \pm 35$ & 0.83 \\
\hline LDL-cholesterol (mg/dL) & $99 \pm 28$ & $98 \pm 29$ & $96 \pm 25$ & $96 \pm 30$ & 0.81 \\
\hline HDL-cholesterol (mg/dL) & $44 \pm 13$ & $45 \pm 12$ & $44 \pm 13$ & $42 \pm 13$ & 0.077 \\
\hline $\mathrm{CRP}(\mathrm{mg} / \mathrm{l})$ & $3.0(1.0-10.9)$ & $5.8(1.1-18.3)$ & $3.0(1.0-9.0)$ & $2.1(1.0-8.0)$ & 0.0001 \\
\hline LVEF & $0.59 \pm 0.14$ & $0.56 \pm 0.16$ & $0.61 \pm 0.13$ & $0.60 \pm 0.13$ & 0.0020 \\
\hline Procedure (\%) & & & & & 0.069 \\
\hline CABG & 17.9 & 21.3 & 19.0 & 13.4 & \\
\hline $\mathrm{PCl}$ & 82.1 & 78.7 & 81.0 & 86.6 & \\
\hline Multivessel disease (\%) & 57.6 & 60.8 & 55.8 & 56.1 & 0.45 \\
\hline LMT disease (\%) & 6.1 & 6.7 & 5.4 & 6.3 & 0.83 \\
\hline LAD disease $(\%)$ & 74.1 & 73.5 & 75.4 & 73.2 & 0.84 \\
\hline Statins (\%) & 14.0 & 12.9 & 11.9 & 17.8 & 0.19 \\
\hline$\beta$-blocker (\%) & 26.3 & 23.3 & 24.3 & 31.8 & 0.12 \\
\hline ARB/ACEI (\%) & 43.7 & 42.9 & 44.0 & 44.3 & 0.95 \\
\hline Calcium antagonist (\%) & 41.3 & 41.9 & 41.7 & 40.0 & 0.91 \\
\hline
\end{tabular}

\begin{tabular}{|c|c|c|c|c|}
\hline & \multicolumn{3}{|l|}{ Serum CRP } & \multirow[b]{2}{*}{$P$ value } \\
\hline & $\begin{array}{l}\leq 1.4 \mathrm{mg} / \mathrm{L} \\
(\mathrm{n}=241)\end{array}$ & $\begin{array}{l}1.5-7.0 \mathrm{mg} / \mathrm{L} \\
(\mathrm{n}=241)\end{array}$ & $\begin{array}{l}\geq 7.1 \mathrm{mg} / \mathrm{L} \\
(\mathrm{n}=239)\end{array}$ & \\
\hline Male gender (\%) & 68.9 & 72.8 & 71.7 & 0.48 \\
\hline Age (years) & $65 \pm 9$ & $66 \pm 10$ & $68 \pm 10$ & 0.010 \\
\hline Duration of HD (years) & $4.4(0.8-11.8)$ & $3.6(1.3-11.6)$ & $3.5(1.3-10.2)$ & 0.98 \\
\hline Diabetes (\%) & 58.9 & 52.7 & 61.5 & 0.13 \\
\hline Hypertension (\%) & 58.1 & 60.6 & 60.7 & 0.81 \\
\hline Dyslipidaemia (\%) & 25.3 & 29.5 & 33.1 & 0.20 \\
\hline Smoking (\%) & 29.5 & 30.7 & 27.8 & 0.85 \\
\hline Body mass index $\left(\mathrm{kg} / \mathrm{m}^{2}\right)$ & $21.4 \pm 2.9$ & $21.6 \pm 3.3$ & $21.5 \pm 3.5$ & 0.77 \\
\hline $\operatorname{PAD}(\%)$ & 34.4 & 37.8 & 43.9 & 0.096 \\
\hline Stroke (\%) & 17.2 & 20.5 & 19.3 & 0.64 \\
\hline GNRI & $95.9 \pm 7.6$ & $95.0 \pm 8.3$ & $92.6 \pm 9.8$ & $<0.0001$ \\
\hline Haemoglobin (g/dL) & $10.8 \pm 1.2$ & $10.6 \pm 1.3$ & $10.4 \pm 1.4$ & 0.14 \\
\hline
\end{tabular}


Table 1 Continued

\begin{tabular}{|c|c|c|c|c|}
\hline & Serum CRI & & & \\
\hline & $\begin{array}{l}\leq 1.4 \mathrm{mg} / \mathrm{L} \\
(\mathrm{n}=241)\end{array}$ & $\begin{array}{l}1.5-7.0 \mathrm{mg} / \mathrm{L} \\
(\mathrm{n}=241)\end{array}$ & $\begin{array}{l}\geq 7.1 \mathrm{mg} / \mathrm{L} \\
(\mathrm{n}=239)\end{array}$ & $P$ value \\
\hline Albumin (g/dL) & $3.7 \pm 0.3$ & $3.6 \pm 0.3$ & $3.5 \pm 0.2$ & $<0.0001$ \\
\hline Total cholesterol (mg/dL) & $166 \pm 35$ & $167 \pm 30$ & $171 \pm 43$ & 0.53 \\
\hline LDL-cholesterol (mg/dL) & $93 \pm 26$ & $96 \pm 28$ & $104 \pm 33$ & 0.013 \\
\hline HDL-cholesterol (mg/dL) & $47 \pm 14$ & $43 \pm 12$ & $42 \pm 11$ & 0.0026 \\
\hline $\mathrm{CRP}(\mathrm{mg} / \mathrm{l})$ & $1.0(0.8-1.1)$ & $3.0(2.0-5.0)$ & $19.0(11.0-43.0)$ & $<0.0001$ \\
\hline LVEF & $0.62 \pm 0.12$ & $0.58 \pm 0.14$ & $0.58 \pm 0.15$ & 0.018 \\
\hline Procedure (\%) & & & & 0.15 \\
\hline CABG & 16.7 & 15.3 & 21.8 & \\
\hline $\mathrm{PCl}$ & 83.3 & 84.7 & 78.2 & \\
\hline Multivessel disease (\%) & 53.9 & 57.3 & 61.5 & 0.24 \\
\hline LMT disease (\%) & 5.4 & 7.5 & 5.4 & 0.56 \\
\hline LAD disease $(\%)$ & 77.4 & 68.3 & 76.5 & 0.074 \\
\hline Statins (\%) & 12.1 & 12.9 & 16.9 & 0.32 \\
\hline$\beta$-blocker (\%) & 31.5 & 23.0 & 24.2 & 0.11 \\
\hline ARB/ACEI (\%) & 45.1 & 42.1 & 43.9 & 0.82 \\
\hline 2calcium antagonist (\%) & 44.2 & 38.8 & 40.9 & 0.53 \\
\hline
\end{tabular}

Bold data are expressed as mean \pm SD or median (IQR).

ACEl, Angiotensin-converting-enzyme inhibitor; ARB, Angiotensin II Receptor Blocker; CABG, coronary artery bypass grafting; CRP, C reactive protein; GNRI, geriatric nutritional risk index; HD, haemodialysis; HDL, high density lipoprotein; LAD, left anterior descending artery; LDL, low deinsity lipoprotein; LMT, left main trunk; LVEF, left ventricular ejection fraction; PAD, peripheral artery disease; PCI, percutaneous coronary intervention.

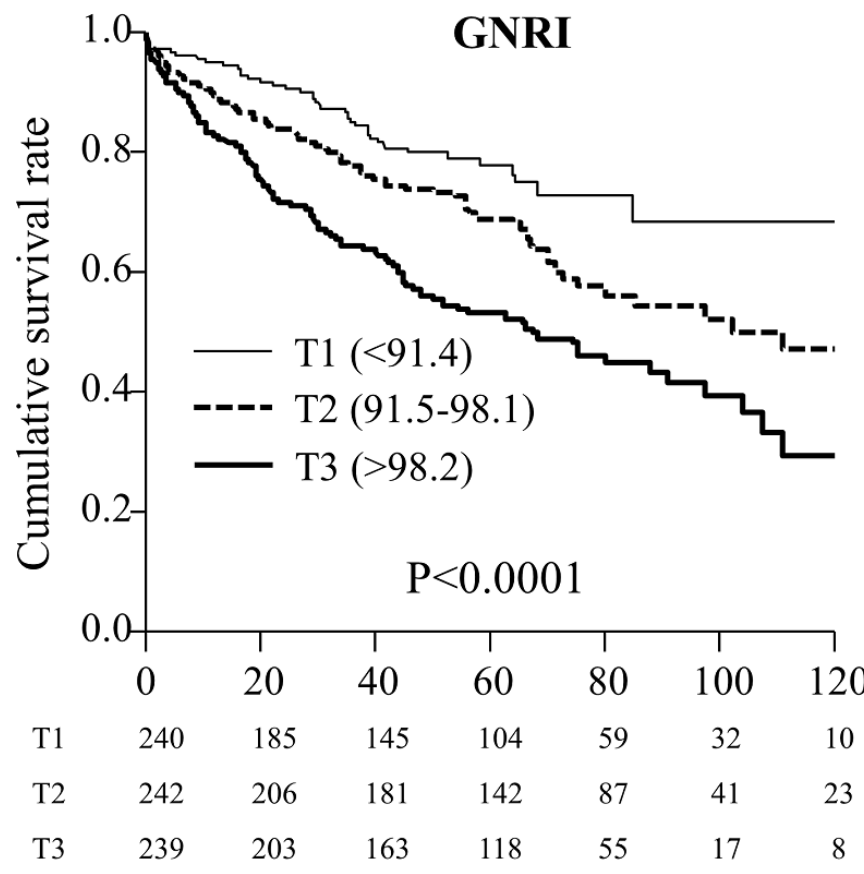

Follow-up period (months)

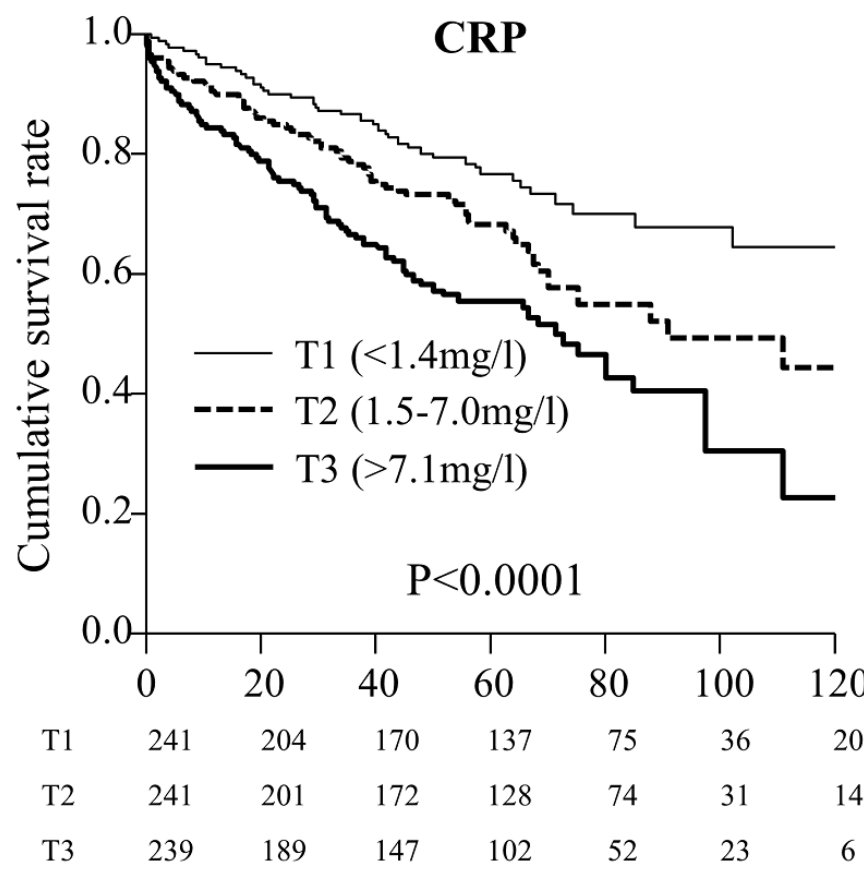

Follow-up period (months)

Figure 1 All-cause survival after coronary intervention among tertiles according to GNRI and CRP levels. CRP, C reactive protein; GNRI, Geriatric Nutritional Risk Index. 


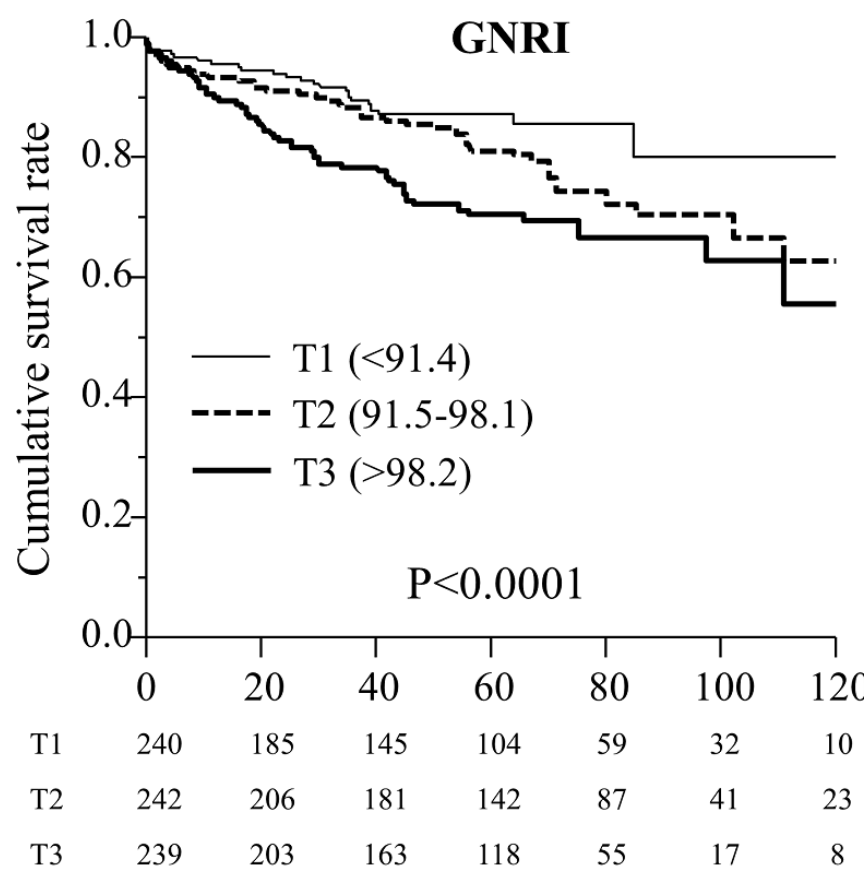

Follow-up period (months)

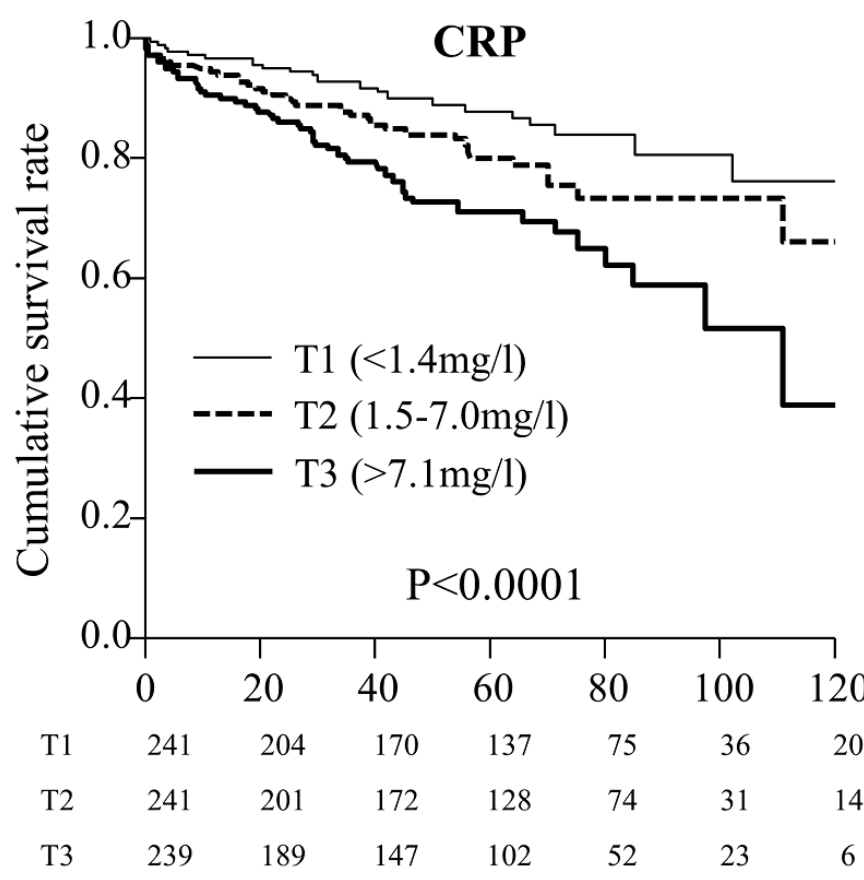

Follow-up period (months)

Figure 2 Cardiovascular survival after coronary intervention among tertiles according to GNRI and CRP levels. CRP, C reactive protein; GNRI, Geriatric Nutritional Risk Index.

and LVEF as covariates with $\mathrm{p}<0.05$ by univariate analysis, a declined GNRI (HR 2.40, 95\% CI 1.58 to 3.74, p<0.0001 for T1 vs T3) and elevated CRP (HR 2.31, 95\% CI 1.58 to
3.43, $\mathrm{p}<0.0001$ for T3 vs T1) were identified as independent predictors of all-cause mortality (table 2). Similarly, both variables could predict CVD-cause mortality as well

Table 2 Predictive value of GNRI and CRP for cardiovascular-cause and all-cause mortality

\begin{tabular}{|c|c|c|c|c|}
\hline & \multicolumn{2}{|l|}{ Non-adjusted } & \multicolumn{2}{|l|}{ Adjusted* } \\
\hline & HR (95\% Cl) & $P$ value & HR (95\% Cl) & $P$ value \\
\hline \multicolumn{5}{|l|}{ CVD-cause mortality } \\
\hline T2 & 1.61 (0.96 to 2.77$)$ & 0.073 & 1.67 (0.94 to 3.12$)$ & 0.081 \\
\hline $\mathrm{T} 1$ & 2.95 (1.82 to 3.87$)$ & $<0.0001$ & 2.45 (1.39 to 4.54$)$ & 0.0015 \\
\hline CRP (vs T1) & & $<0.0001$ & & 0.0009 \\
\hline T2 & 1.44 (0.89 to 2.37 ) & 0.13 & 1.58 (0.89 to 2.84$)$ & 0.11 \\
\hline T3 & 2.56 (1.63 to 4.11$)$ & $<0.0001$ & 2.98 (1.77 to 5.22$)$ & $<0.0001$ \\
\hline Log CRP & 2.09 (1.57 to 2.77) & $<0.0001$ & 1.83 (1.37 to 2.43 ) & $<0.0001$ \\
\hline $\mathrm{T} 1$ & 2.99 (2.09 to 4.39$)$ & $<0.0001$ & 2.40 (1.58 to 3.74$)$ & $<0.0001$ \\
\hline GNRI (continuous) & 0.95 (0.93 to 0.96$)$ & $<0.0001$ & 0.96 (0.94 to 0.98$)$ & $<0.0001$ \\
\hline CRP (vs T1) & & $<0.0001$ & & $<0.0001$ \\
\hline $\mathrm{T} 2$ & 1.53 (1.07 to 2.20$)$ & 0.018 & 1.39 (0.93 to 2.10$)$ & 0.10 \\
\hline T3 & 2.46 (1.76 to 3.49 ) & $<0.0001$ & 2.31 (1.58 to 3.43 ) & $<0.0001$ \\
\hline Log CRP & 1.89 (1.53 to 2.33 ) & $<0.0001$ & 1.68 (1.35 to 2.08$)$ & $<0.0001$ \\
\hline
\end{tabular}

${ }^{*}$ Adjusted for age, multivessel disease and LVEF as covariates with $\mathrm{p}<0.05$ by univariate analysis.

CRP, C reactive protein; CVD, cardiovascular disease; GNRI, Geriatric Nutritional Risk Index; LVEF, left ventricular ejection fraction. 


\section{All-cause mortality}

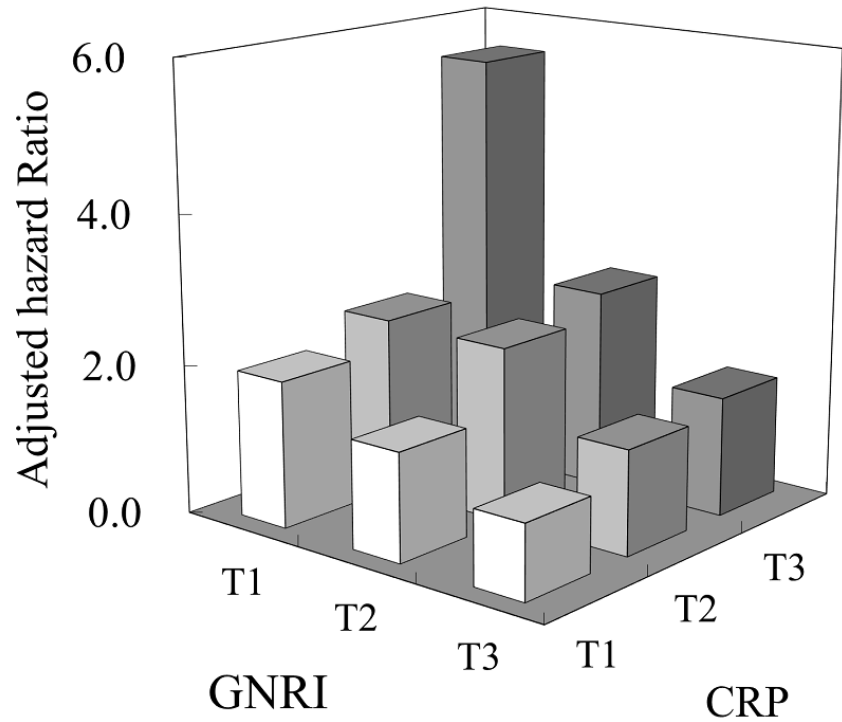

$\mathrm{P}<0.0001$ for trend

\section{CVD mortality}

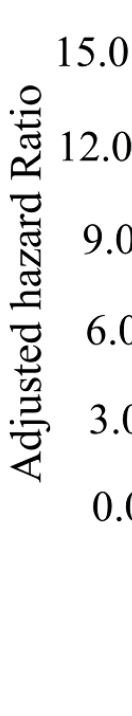

(HR 2.45, 95\% CI 1.39 to $4.54, \mathrm{p}=0.0015$ for T1 vs T3 of the GNRI and HR 2.98, 95\% CI 1.77 to 5.22, $\mathrm{p}<0.0001$ for T3 vs T1 of the CRP). In addition, the GNRI and log CRP as continuous value were also independent predictors of all-cause mortality (HR $0.96,95 \%$ CI 0.94 to 0.98 , $\mathrm{p}<0.0001$ and HR $1.68,95 \%$ CI 1.35 to $2.08, \mathrm{p}<0.0001$ ) and CVD mortality (HR 0.96, 95\% CI 0.94 to 0.98 , $\mathrm{p}<0.0001$ and HR $1.83,95 \%$ CI 1.37 to $2.43, \mathrm{p}<0.0001$ ), respectively (table 2 ). In addition, when diabetes, hypertension, duration of HD and haemoglobin as clinically important factors were added the multivariate Cox model, the GNRI (HR 0.96, 95\% CI 0.94 to 0.97 , p $<0.0001$ for CVD mortality and HR 0.96 , 95\% CI 0.94 to 0.98 , $\mathrm{p}<0.0001$ for all-cause mortality) and $\log$ CRP (HR 1.81,
95\% CI 1.35 to 2.41, $\mathrm{p}<0.0001$ for CVD mortality and HR $1.70,95 \%$ CI 1.34 to $2.11, \mathrm{p}<0.0001$ for all-cause mortality) were still independent predictors, respectively. In the combined setting of both variables, the risk of mortality was 5.55 times higher $(95 \%$ CI 2.64 to $13.6, p<0.0001)$ in the T1 of the GNRI with the T3 of the CRP than in the T3 of the GNRI with the T1 of the CRP (figure 3). Similar results were also obtained for CVD-cause mortality (HR $14.9,95 \%$ CI 5.26 to $247.4, \mathrm{p}<0.0001)$. Furthermore, the addition of both the GNRI and CRP to a prediction model based on established risk factors-including age, multivessel disease and LVEF as covariates with $\mathrm{p}<0.05$ by univariate analysis-improved the C-index $(0.648$ to $0.724, \mathrm{p}<0.0001)$, NRI $(0.539, \mathrm{p}<0.0001)$ and IDI $(0.081$,

Table 3 Discrimination of each predicting models for cardiovascular-cause and all-cause mortality using C-index, net reclassification improvement (NRI) and integrated discrimination improvement (IDI)

\begin{tabular}{|c|c|c|c|c|c|c|}
\hline & C-index $(95 \% \mathrm{Cl})$ & P value & NRI & $P$ value & IDI & $P$ value \\
\hline \multicolumn{7}{|c|}{ CVD-cause mortality } \\
\hline Established risk* & 0.630 (0.562 to 0.698$)$ & Reference & & Reference & & Reference \\
\hline$+\mathrm{CRP}$ & $0.678(0.611$ to 0.745$)$ & 0.0053 & 0.364 & 0.0011 & 0.021 & 0.017 \\
\hline +GNRI and CRP & 0.718 (0.659 to 0.776$)$ & 0.0002 & 0.510 & $<0.0001$ & 0.056 & $<0.0001$ \\
\hline Established risk* & 0.648 (0.596 to 0.699$)$ & Reference & & Reference & & Reference \\
\hline$+\mathrm{GNRI}$ & 0.707 (0.660 to 0.754$)$ & 0.0036 & 0.510 & $<0.0001$ & 0.060 & $<0.0001$ \\
\hline$+\mathrm{CRP}$ & $0.687(0.637$ to 0.736$)$ & 0.0018 & 0.360 & $<0.0001$ & 0.031 & $<0.0001$ \\
\hline +GNRI and CRP & 0.724 (0.678 to 0.770$)$ & 0.0002 & 0.539 & $<0.0001$ & 0.081 & $<0.0001$ \\
\hline
\end{tabular}

*Including age, multivessel disease and LVEF as covariates with $\mathrm{p}<0.05$ by univariate analysis.

CRP, C reactive protein; CVD, cardiovascular disease; GNRI, Geriatric Nutritional Risk Index ; LVEF, left ventricular ejection fraction. 
$\mathrm{p}<0.0001$ ) more than each alone (table 3). Similar results were also obtained for CVD mortality (C-index 0.630 to $0.718, \mathrm{p}=0.0002$, NRI $0.510, \mathrm{p}<0.0001$ and IDI 0.056 , $\mathrm{p}<0.0001)$.

\section{DISCUSSION}

Until now, the consistent poorer outcome after, regardless of percutaneous, ${ }^{7}$ even in the modern DES era, ${ }^{8}$ or surgical coronary revascularisation, ${ }^{4-6}$ was considered to be due to various reasons such as complex and/or massive calcified coronary lesions, ${ }^{23}$ the presence of multivessel disease or an intolerance for procedural invasion due to accelerated systemic atherosclerosis in chronic HD patients. ${ }^{6}$ Thus, our results suggest that preprocedural PEW and/or chronic inflammation status should be newly added to such numerous prognostic factors after coronary revascularisation in this high-risk population.

We have reported that both a declined GNRI and elevated CRP are closely associated with abnormalities of the ankle-brachial index (ABI) and that the combination of these variables additively increases CVD-cause and allcause mortality risks in HD patients ${ }^{24}$. Other studies have also reported that an abnormal ABI reflects not only PAD but also a systemic atherosclerosis such as overall CVD, including coronary or cerebrovascular diseases. ${ }^{25}{ }^{26}$ Thus, our previous report might manifest so-called malnutrition, inflammation and atherosclerosis syndrome in patients with CKD. ${ }^{13}{ }^{14}$ In this context, our present findings might be appropriately explained by these previous findings, as HD patients undergoing coronary intervention, regardless of whether it is surgical or percutaneous, are consistently considered to be a highly atherosclerotic group, even among average HD patients.

Moreover, we have already reported that a preprocedural lower BMI and elevated CRP are independently associated with an incidence of lower limb amputation after infrapopliteal bypass surgery in HD patients with critical limb ischemia (HR $0.86,95 \%$ CI 0.76 to 0.97 , $\mathrm{p}=0.014$ and HR $1.06,95 \%$ CI 1.01 to $1.11, \mathrm{p}=0.014$, respectively). However, interestingly, the predictability of both of these variables were not significant in non-HD patients (HR $0.89,95 \%$ CI 0.57 to $1.32, \mathrm{p}=0.52$, and HR $1.02,95 \%$ CI 0.98 to $1.06, \mathrm{p}=0.31$, respectively).$^{27}$ Referring to these results, preprocedural malnutrition and inflammation status might possibly CKD-specifically affect poorer outcomes after, regardless of coronary or lower extremity intervention, compared with non-HD patients.

In addition, it has been reported that predictability for mortality with the GNRI is broadly comparable with the diagnostic criteria of PEW recommended by the International Society of Renal Nutrition and Metabolism (PEWISRNM) (C-index: 0.819 vs $0.820, \mathrm{p}=0.82) .{ }^{28}$ Although use of the PEW-ISRNM, including measurement of the mid-arm muscle circumference area or daily proteinenergy intake, is accurate to assess PEW, it might be troublesome. In contrast, the GNRI value is easily obtained from daily clinical practice. Therefore, the GNRI may be a useful indicator over the PEW-ISRNM to assess malnutrition in HD patients. In this context, physicians should pay more attention to these pre-procedural comorbidities in this high-risk population.

There are several limitations in the present study. First, all the study subjects were Japanese, who reportedly have a better prognosis compared with patients in the United States and Europe. ${ }^{29}$ Second, study subjects were included from only two centres. Third, we did not evaluate $\mathrm{HD}$ patients without $\mathrm{CAD}$ as the control group. Thus, we could not demonstrate more effect of these comorbidities status in patients with CAD compared with those without. Four, we did not consider impact of changes in GNRI and CRP during follow-up period on outcomes. Changes in BMI or albumin is reportedly associated with mortality. ${ }^{30}$

In conclusion, a preprocedural declined GNRI and elevated CRP, which reflect PEW and chronic inflammation status, are closely associated with CVD-cause and all-cause mortality after coronary revascularisation in chronic HD patients. Furthermore, the combination of both variables could not only stratify the risk of mortalities but also improve the predictability when adding on established risk factors, including age, multivessel disease or LVEF.

Contributorship Statement Conception and design of the study; YK, HI and HT. Generation, collection, assembly, analysis and/or interpretation of data; YK, SO, RI, $\mathrm{NU}$ and $\mathrm{HT}$. Drafting and/or revision of the manuscript; YK, HI andHT. Approval of the final version of the manuscript; YK, HI, HT, SO, RI, NU and TM.

Funding The authors have not declared a specific grant for this research from any funding agency in the public, commercial or not-for-profit sectors.

Competing interests $\mathrm{HI}$ received lecture fees from Astellas Pharma, Astrazeneca, Bayer Pharma, Bristol-Myers Squibb, Chugai Pharma, Daiichi Sankyo and Otsuka Pharma. TM received lecture fees from Bayer Pharmaceutical, Daiichi Sankyo, Dainippon Sumitomo Pharma, Kowa, MSD K.K., Mitsubishi Tanabe Pharma, Nippon Boehringer Ingelheim, Novartis Pharma K.K., Pfizer Japan, Sanofi-aventis K.K and Takeda Pharmaceutical. TM received unrestricted research grant for Department of Cardiology, Nagoya University Graduate School of Medicine from Astellas Pharma, Daiichi Sankyo, Dainippon Sumitomo Pharma, Kowa, MSD K.K., Mitsubishi Tanabe Pharma, Nippon Boehringer Ingelheim, Novartis Pharma K.K., Otsuka Pharma, Pfizer Japan, Sanofi-aventis K.K., Takeda Pharmaceutica, Teijin Pharma.

Patient consent for publication Not required.

Ethics approval The study protocol and chart reviews used were approved by the institutional ethics of both hospitals and conducted in accordance with the Declaration of Helsinki.

Provenance and peer review Not commissioned; externally peer reviewed. Data availability statement Data are available on reasonable request.

Open access This is an open access article distributed in accordance with the Creative Commons Attribution Non Commercial (CC BY-NC 4.0) license, which permits others to distribute, remix, adapt, build upon this work non-commercially, and license their derivative works on different terms, provided the original work is properly cited, appropriate credit is given, any changes made indicated, and the use is non-commercial. See: http://creativecommons.org/licenses/by-nc/4.0/.

ORCID iDs

Hideki Ishii http://orcid.org/0000-0003-4348-0123

Hiroshi Takahashi http://orcid.org/0000-0002-3620-1352

\section{REFERENCES}

1 Sarnak MJ, Levey AS, Schoolwerth AC, et al. Kidney disease as a risk factor for development of cardiovascular disease: a 
statement from the American heart association councils on kidney in cardiovascular disease, high blood pressure research, clinical cardiology, and epidemiology and prevention. Circulation 2003;108:2154-69.

2 Joki $\mathrm{N}$, Hase H, Nakamura R, et al. Onset of coronary artery disease prior to initiation of haemodialysis in patients with end-stage renal disease. Nephrol Dial Transplant 1997;12:718-23.

3 Herzog CA. Kidney disease in cardiology. Nephrol Dial Transplant 2011;26:46-50.

4 Hillis GS, Croal BL, Buchan KG, et al. Renal function and outcome from coronary artery bypass grafting: impact on mortality after a 2.3year follow-up. Circulation 2006;113:1056-62.

5 Cooper WA, O'Brien SM, Thourani VH, et al. Impact of renal dysfunction on outcomes of coronary artery bypass surgery: results from the Society of thoracic surgeons national adult cardiac database. Circulation 2006;113:1063-70.

6 Yamauchi T, Miyata H, Sakaguchi T, et al. Coronary artery bypass grafting in hemodialysis-dependent patients: analysis of Japan adult cardiovascular surgery database. Circ J 2012;76:1115-20.

7 Natsuaki M, Furukawa Y, Morimoto T, et al. Impact of diabetes on cardiovascular outcomes in hemodialysis patients undergoing coronary revascularization. Circ J 2011;75:1616-25.

8 Otsuka Y, Ishiwata S, Inada T, et al. Comparison of haemodialysis patients and non-haemodialysis patients with respect to clinical characteristics and 3-year clinical outcomes after sirolimus-eluting stent implantation: insights from the Japan multi-centre postmarketing surveillance registry. Eur Heart J 2011;32:829-37.

9 Fouque D, Kalantar-Zadeh K, Kopple J, et al. A proposed Nomenclature and diagnostic criteria for protein-energy wasting in acute and chronic kidney disease. Kidney Int 2008;73:391-8.

10 Kopple JD, Lecture MA. Protein-Energy malnutrition in maintenance dialysis patients. Am J Clin Nutr 1996;1997:1544-57.

11 Mehrotra R, Kopple JD. Nutritional management of maintenance dialysis patients: why aren't we doing better? Annu Rev Nutr 1997;65:1544-57.

12 Takahashi $\mathrm{H}$, Ito $\mathrm{Y}$, Ishii $\mathrm{H}$, et al. Geriatric nutritional risk index accurately predicts cardiovascular mortality in incident hemodialysis patients. J Cardiol 2014;64:32-6.

13 Kalantar-Zadeh K, Kopple JD. Relative contributions of nutrition and inflammation to clinical outcome in dialysis patients. Am J Kidney Dis 2001;38:1343-50.

14 Stenvinkel $\mathrm{P}$, Heimbürger O, Paultre F, et al. Strong association between malnutrition, inflammation, and atherosclerosis in chronic renal failure. Kidney Int 1999;55:1899-911.

15 Takahashi $\mathrm{R}$, Ito $\mathrm{Y}$, Takahashi $\mathrm{H}$, et al. Combined values of serum albumin, C-reactive protein and body mass index at dialysis initiation accurately predicts long-term mortality. Am J Nephrol 2012;36:136-43.
16 Bouillanne O, Morineau G, Dupont C, et al. Geriatric nutritional risk index: a new index for evaluating at-risk elderly medical patients. Am $J$ Clin Nutr 2005;82:777-83.

17 Haneda M, Noda M, Origasa $\mathrm{H}$, et al. Japanese clinical practice guideline for diabetes 2016. Diabetol Int 2018;9:1-45.

18 Umemura S, Arima H, Arima S, et al. The Japanese Society of hypertension guidelines for the management of hypertension (JSH 2019). Hypertens Res 2019;42:1235-481.

19 Kinoshita M, Yokote K, Arai H, et al. Japan atherosclerosis Society (JAS) guidelines for prevention of atherosclerotic cardiovascular diseases 2017. J Atheroscler Thromb 2018;25:846-984.

20 Yamada K, Furuya R, Takita T, et al. Simplified nutritional screening tools for patients on maintenance hemodialysis. Am J Clin Nutr 2008;87:106-13.

21 DeLong ER, DeLong DM, Clarke-Pearson DL. Comparing the areas under two or more correlated receiver operating characteristic curves: a nonparametric approach. Biometrics 1988;44:837-45.

22 Pencina MJ, D'Agostino RB, D'Agostino RB, et al. Evaluating the added predictive ability of a new marker: from area under the ROC curve to reclassification and beyond. Stat Med 2008;27:157-72.

23 Naidu SS, Selzer F, Jacobs A, et al. Renal insufficiency is an independent predictor of mortality after percutaneous coronary intervention. Am J Cardiol 2003;92:1160-4

24 Ishii $\mathrm{H}$, Takahashi $\mathrm{H}$, Ito $\mathrm{Y}$, et al. The association of ankle brachial index, protein-energy wasting, and inflammation status with cardiovascular mortality in patients on chronic hemodialysis. Nutrients 2017:9:416.

25 Ono K, Tsuchida A, Kawai H, et al. Ankle-Brachial blood pressure index pre- dicts all-cause and cardiovascular mortality in hemodialysis patients. J AmSoc Nephrol 2003;14:1591-8.

26 Tanaka M, Ishii H, Aoyama T, et al. Ankle brachial pressure index but not brachial-ankle pulse wave velocity is a strong predictor of systemic atherosclerotic morbidity and mortality in patients on maintenance hemodialysis. Atherosclerosis 2011;219:643-7.

27 Kumada Y, Nogaki H, Ishii H, et al. Clinical outcome after infrapopliteal bypass surgery in chronic hemodialysis patients with critical limb ischemia. J Vasc Surg 2015;61:400-4.

28 Takahashi $\mathrm{H}$, Inoue $\mathrm{K}$, Shimizu K, et al. Comparison of nutritional risk scores for predicting mortality in Japanese chronic hemodialysis patients. J Ren Nutr 2017;27:201-6.

29 Sekikawa A, Ueshima H, Kadowaki T, et al. Less subclinical atherosclerosis in Japanese men in Japan than in white men in the United States in the post-World War II birth cohort. Am J Epidemiol 2007;165:617-24.

30 Pifer TB, McCullough KP, Port FK, et al. Mortality risk in hemodialysis patients and changes in nutritional indicators: DOPPS. Kidney Int 2002;62:2238-45. 